\title{
$O$ tratamento da heterogeneidade em uma pedagogia coletiva: maneiras de fazer de professoras alfabetizadoras
}

\author{
Nayanne Nayara Torres da Silva*
}

Alexsandro da Silva**

\section{Resumo}

O presente estudo insere-se no âmbito das discussões sobre saberes e práticas de professores no atendimento à heterogeneidade de conhecimentos sobre a leitura e a escrita dos aprendizes. Nessa direção, buscamos compreender as ações mobilizadas por alfabetizadoras para, em meio as situações coletivas e padronizadas de ensino, tratar as necessidades de aprendizagem de alguns alunos. Para isso, analisamos as práticas de duas professoras do $1^{\circ}$ ano do Ensino Fundamental da rede municipal de ensino da cidade de Caruaru-PE, Brasil, adotando, como caminho teórico-metodológico, a abordagem qualitativa de pesquisa. Os dados da investigação, tratados por meio da análise temática de conteúdo e obtidos por meio de entrevistas semiestruturadas e de observações em sala de aula, evidenciaram a utilização de alguns "esquemas de ação" e "táticas" por parte das professoras para, em meio às situações coletivas e padronizadas de ensino, atender às necessidades de alguns alunos.

Palavras-chave: Alfabetização. Heterogeneidade. Práticas.

* Mestra em Educação Contemporânea pela Universidade Federal de Pernambuco - Centro Acadêmico do Agreste (UFPECAA).

** Doutor em Educação pela Universidade Federal de Pernambuco (UFPE). Professor do Centro Acadêmico do Agreste da Universidade Federal de Pernambuco (UFPE).

PERSPECTIVA, Florianópolis, v. 35, n. 1, p. 283-299, jan./mar. 2017 http://www.perspectiva.ufsc.br 


\section{Introdução}

A alfabetização coletiva nas escolas é, atualmente, uma regra, mas não podemos esquecer que esse modo de ensino é uma construção histórica (CHARTIER, 2007b). No Brasil, no período Colonial e até mesmo no Império, quando a educação ainda não era um direito de todos e não havia a obrigatoriedade de frequência à escola, observava-se intensa presença do ensino individual (FARIA FILHO; VIDAL, 2000), muitas vezes realizado em casa ou em espaços inadequados de sala de aula. Nesse modo de ensino, o preceptor ou professor ensinava cada aluno individualmente, mesmo quando sua classe era constituída por vários alunos.

Devido, principalmente, à necessidade de generalizar a instrução para um grande número de indivíduos, isto é, a escolarização de massa (FARIA FILHO; VIDAL, 2000; CHARTIER, 2007b), o ensino individual deu lugar a uma pedagogia coletiva. No Brasil, na época da República, instalam-se as escolas seriadas e difunde-se o método simultâneo, no qual, "De acordo com sua faixa etária e seu nível de conhecimento, os alunos passariam a se organizar em turmas classificadas em séries e o professor ou professora passaria a desenvolver atividades coletivas com eles, utilizando um mesmo material didático." (BATISTA; GALVÃO; KINKLE, 2002, p. 27). É esse o modelo de organização do ensino que é usado, de modo geral, até os dias atuais, nas escolas brasileiras.

É preciso, porém, não esquecer que, apesar de agrupados em uma mesma série ou ano escolar, os alunos não aprendem ao mesmo tempo e da mesma maneira, o que torna mais difícil, conforme salienta Chartier (2007b), a gestão coletiva do trabalho na sala de aula, desafiando os professores a ensinar, simultaneamente, a todos e a cada um.

Considerando que, no espaço da sala de aula, os saberes e as práticas dos professores alfabetizadores são (re)inventados cotidianamente na tentativa de desenvolver uma pedagogia diferenciada, que, conforme observa Chartier (2007a), impõe-se com mais evidência na classe de alfabetização, desenvolvemos uma pesquisa que visou a investigar como professoras do $1^{\circ}$ ano do Ensino Fundamental atendiam, nas situações coletivas e padronizadas de ensino, a heterogeneidade de conhecimentos dos alunos sobre a leitura e a escrita.

Nessa direção, apresentaremos, inicialmente, algumas reflexões teóricas sobre diferentes perspectivas de alfabetização e suas implicações no tratamento da heterogeneidade, assim como sobre os saberes e as ações docentes no cotidiano da sala de aula. Em seguida, após situarmos os aspectos metodológicos da pesquisa, explicitaremos e discutiremos os resultados encontrados, assim como teceremos algumas considerações finais. 


\section{Alfabetização: diferentes perspectivas, diferentes implicações no tratamento da heterogeneidade}

Ao longo da história da alfabetização brasileira, dois grandes grupos de métodos constituíramse de maneira hegemônica: os sintéticos (soletração, silabação e método fônicos), que partem das unidades menores da língua (letra, sílaba ou fonema), e os analíticos (palavração, sentenciação e método de contos), que, ao contrário, partem das unidades linguísticas maiores (palavra, frase ou texto).

Embora tivessem pontos de partida diferentes, tais métodos não se diferenciavam quanto à maneira de conceber a alfabetização, que era vista como a aquisição de um código de transcrição da fala, que seria aprendido por meio da repetição e memorização. Assim, “[...] apesar das diferenças que aparentam, [os métodos tradicionais] têm uma única e comum teoria de conhecimento subjacente: a visão empirista/associacionista de aprendizagem.” (MORAIS, 2012, p. 27).

No quadro de tais métodos, não se considerava a necessidade de propor aos alunos atividades diferenciadas, que considerassem os diferentes conhecimentos e percursos dos aprendizes, uma vez que as atividades padronizadas e coletivas seriam suficientes para garantir que os aprendizes, tratados como sujeitos homogêneos, memorizassem o código.

No início da década de 1980, com a difusão, no cenário brasileiro, da teoria da Psicogênese da Escrita (FERREIRO; TEBEROSKY, 1999), a tradição dos métodos tradicionais começa a ser questionada. Nesse contexto, instaurou-se uma verdadeira revolução conceitual no campo da alfabetização, deslocando a atenção, conforme esclarece Ferreiro (2001), do "como se ensina" para o "como se aprende".

Se a perspectiva tradicional de alfabetização não estava preocupada com a heterogeneidade de conhecimentos dos aprendizes, a teoria psicogenética da escrita inaugurou, de certo modo, uma atenção a esse fenômeno, ao considerar o aprendiz em sua singularidade. Desse modo, as maneiras pelas quais ele aprende, que são as mais diversas, assumiram um papel central no processo de alfabetização, uma vez que a aprendizagem do sistema de escrita alfabética (doravante SEA) acontece, conforme evidencia essa teoria, de forma gradativa e evolutiva. Nessa perspectiva, os diferentes conhecimentos e percursos de aprendizagem passariam a ser considerados.

No contexto brasileiro, a perspectiva de ciclos de aprendizagem parece ter impulsionado, tal como a Psicogênese da Escrita, a necessidade de respeito aos diferentes tempos e percursos de 
aprendizagem dos alunos. A proposta de ciclos surgiu com o intuito de "[...] regularizar o fluxo de alunos ao longo da escolarização, a fim de assegurar que todos possam cumprir os anos de estudo previstos para o ensino obrigatório, sem interrupções e retenções que inviabilizem a aprendizagem efetiva e uma educação de qualidade" (BARRETTO; SOUSA, 2004, p. 33).

Nessa proposta, visa-se contribuir para o sucesso dos aprendizes na escola e, para isso, ampliase o tempo de aprendizagem dos alunos. Segundo Mainardes (2009), o termo "ciclos" vem sendo utilizado no Brasil, e em outros países, para designar uma forma de organização que supera a perspectiva do regime de seriação, a qual classifica e homogeneíza os aprendizes. Nessa nova forma de organização, o referido autor pontua que "[...] os anos da escolaridade obrigatória são divididos em ciclos de 2, 3 ou 4 anos. A reprovação é possível apenas no final de cada ciclo e, em algumas experiências, ela é totalmente eliminada e substituída por outras formas de progressão dos alunos." (MAINARDES, 2009, p.11).

Essa proposta de correção do fluxo, existente no ideário de ciclo, não é, porém, garantia de pedagogia diferenciada, podendo servir como um mero "descongestionamento" do sistema. Em outras palavras, embora a proposta de ciclos considere a heterogeneidade de conhecimentos, ela não assegura, necessariamente, o atendimento desse fenômeno por meio de práticas de ensino ajustadas às necessidades dos aprendizes.

Em síntese, uma teoria psicológica sobre os processos de construção de conhecimentos sobre a escrita (a "Psicogênese da escrita") e uma outra forma de organização escolar (os ciclos de aprendizagem) impulsionaram uma nova maneira de considerar os diferentes percursos e conhecimentos dos aprendizes e os modos de tratá-los no contexto da sala de aula. No entanto, a materialização de uma pedagogia diferenciada não acontece apenas como decorrência da difusão de novas teorias ou de decretos que instituem mudanças nas formas de organização escolar, pois depende de outros aspectos, dentre os quais os saberes e práticas que os docentes mobilizam em suas ações cotidianas.

\section{Os professores e as suas maneiras de fazer no cotidiano da sala de aula}

As ações desenvolvidas pelos professores, no espaço da sala de aula, mobilizam diferentes saberes construídos ao longo do tempo e da carreira profissional, entre os quais se sobressaem aqueles oriundos da experiência. Segundo Tardif (2008), os saberes experienciais são provenientes das 
experiências dos professores, que são adquiridas por meio de suas práticas cotidianas, e não se encontram, portanto, definidos nem nos currículos, nem nas instituições de formação, muito menos sistematizados como teoria e doutrina. É no exercício diário de sua função, em meio às ações impostas pelos condicionantes do contexto escolar, que esse saber experiencial vai-se constituindo.

Segundo Goigoux (2002), as práticas docentes podem materializar-se por meio de esquemas, que são procedimentos regulares, ou seja, formas organizadas e estabilizadas de ensino que os professores acionam no processo de mediação entre as crianças e os conhecimentos, com vistas a operacionalizar um ensino ajustado às potencialidades dos educandos.

Tais esquemas estão intimamente relacionados aos saberes experienciais e vão sendo estabilizados ao longo do tempo nas ações docentes. Nessas ações, os docentes traçam metas e definem suas práticas de acordo com uma pertinência que é, principalmente, de ordem pragmática, pautando-se, assim, em uma coerência que visa a contemplar diferentes aspectos presentes no cotidiano da sala de aula (CHARTIER, 2007a).

Nessas ações, podem coexistir práticas que se relacionem a perspectivas teóricas consideradas diferenciadas ou mesmo antagônicas. De um ponto de vista teórico, isso pode ser percebido como incoerente quando analisado por aqueles que se encontram fora do ambiente da sala de aula e não compartilham as diferentes tramas nele vivenciadas. Contudo, conforme salienta Chartier (2007a), do ponto de vista dos "saberes da ação", os procedimentos adotados pelos docentes são organizados dentro de um sistema de forte coerência pragmática, que tem em diversas fontes a base de suas decisões e a consolidação de seus programas de ação.

Nas ações cotidianas, o docente também reinventa e reformula as teorias acadêmicas, as prescrições legais, as regras, ou seja, “as estratégias”, e utiliza-as conforme as suas necessidades, o que poderíamos chamar, apoiando-nos em Certeau (1994), de “táticas”. Segundo esse autor, estratégia é “o cálculo (ou a manipulação) das relações de forças que se torna possível a partir do momento em que um sujeito de querer e poder (uma empresa, um exército, uma cidade, uma instituição científica) pode ser isolado". Em outras palavras, é o espaço dos que determinam o que deve ser feito, dos que impõem. Já a tática "não tem lugar senão o do outro. E por isso deve jogar com o terreno que lhe é imposto tal como o organiza a lei de uma força estranha" (1994, p. 100). Trata-se, portanto, do lugar da ação no qual se modifica o instituído, subverte-se o prescrito.

Tais modificações fazem parte dos movimentos de inovação didática e pedagógica da prática docente, pois são os "tateamentos incessantes, as adaptações locais, as modificações provisórias" 
(CHARTIER, 2000, p. 164), ou seja, os fazeres ordinários da classe, que podem conduzir ou não a mudanças nas práticas. Desse modo, o professor apropria-se das discussões teóricas difundidas no meio acadêmico, da própria organização escolar a qual está submetido e de outras fontes para instituir suas maneiras de ensinar.

\section{O desenho metodológico da pesquisa}

Para atender ao objetivo do estudo, que consistiu em investigar as ações mobilizadas por professoras alfabetizadoras para, em meio às situações coletivas e padronizadas de ensino, tratar a heterogeneidade de conhecimentos dos alunos sobre a leitura e a escrita, pautamo-nos em uma abordagem qualitativa, que, segundo André (1995), caracteriza-se pela ênfase maior no processo, e não no produto, e tem o pesquisador como instrumento principal na produção e análise dos dados. Além disso, a preocupação com os significados, a utilização de dados descritivos e também da indução são características dessa abordagem.

Para participar da pesquisa, selecionamos duas professoras - consideradas, na rede municipal de ensino na qual trabalhavam, como boas alfabetizadoras ${ }^{1}$ - que atuavam em turmas do $1^{\circ}$ ano do Ensino Fundamental de escolas públicas municipais da cidade de Caruaru-PE, Brasil. Com o objetivo de manter o anonimato dos participantes, as docentes serão tratadas, neste artigo, por Beatriz e Irene, e os nomes de seus alunos também serão fictícios. No Quadro 1, a seguir, apresentamos o perfil das professoras investigadas quanto à formação e à experiência profissional:

Quadro 1 - Perfil das professoras participantes da pesquisa

\begin{tabular}{|c|c|c|c|c|}
\hline \multirow{2}{*}{ Professoras } & \multicolumn{2}{|c|}{ Curso, Ano de conclusão e Rede de ensino } & \multirow{2}{*}{$\begin{array}{l}\text { Experiência } \\
\text { profissional }\end{array}$} & \multirow{2}{*}{$\begin{array}{c}\text { Experiência } \\
\text { profissional na } \\
\text { alfabetização }\end{array}$} \\
\hline & Ensino Médio & Graduação & & \\
\hline Beatriz & $\begin{array}{c}\text { Normal Médio } \\
1996 \\
\text { Pública } \\
\end{array}$ & $\begin{array}{c}\text { Pedagogia } \\
2006 \\
\text { Privada } \\
\end{array}$ & 10 anos & 07 anos \\
\hline Irene & $\begin{array}{l}\text { Normal Médio } \\
\text { (não lembra) } \\
\text { Pública }\end{array}$ & $\begin{array}{c}\text { Pedagogia } \\
\text { Em andamento } \\
\text { (4 período) } \\
\text { Privada }\end{array}$ & 15 anos & 10 anos \\
\hline
\end{tabular}

Fonte: elaborado pelo autor. 
Observando o Quadro 1, percebemos que as professoras apresentam um perfil parecido, com formação profissional inicial no Normal Médio e, posteriormente, no curso de Pedagogia (nesse último caso, concluído por Beatriz em uma instituição privada e em andamento, à época da pesquisa, no caso de Irene, também em uma instituição privada). Ambas possuíam experiência profissional de, pelo menos, uma década e atuaram em turmas de alfabetização por vários anos.

No que diz respeito aos procedimentos metodológicos, realizamos observações das práticas de ensino das professoras, como também entrevistas semiestruturadas, com vistas a analisar e compreender as ações mobilizadas pelas docentes para o tratamento da heterogeneidade de conhecimentos dos alunos sobre a leitura e a escrita.

A observação foi escolhida como procedimento, porque precisávamos ter acesso direto às maneiras pelas quais as ações docentes eram realizadas no ambiente da sala de aula. Para isso, foram observados 10 (dez) dias de aulas de cada professora. Em cada turma, observamos dois grupos de 5 (cinco) dias consecutivos, com um intervalo de uma semana entre eles, com vistas a observar, de segunda a sexta-feira, como as docentes organizavam as atividades, distribuíam os alunos em sala de aula etc.

Utilizamos a entrevista a fim de acessarmos saberes das professoras acerca da heterogeneidade de conhecimentos sobre a leitura e a escrita, como também para obtermos maiores informações e esclarecimentos acerca de suas práticas de alfabetização. As entrevistas foram do tipo semiestruturado, por permitirem maior flexibilidade tanto para o entrevistador quanto para o entrevistado na elaboração das perguntas e das respostas, respectivamente.

O tratamento dos dados foi desenvolvido por meio da análise de conteúdo do tipo temática categorial, envolvendo as etapas sugeridas por Bardin (1977): pré-análise, análise do material (codificação e categorização da informação) e tratamento dos resultados, inferência e interpretação.

Inicialmente, realizamos uma "leitura flutuante" do material obtido por meio das entrevistas e das observações. A partir dessa leitura dos dados, surgiram os temas que foram listados e submetidos aos processos de codificação e categorização, em que as informações foram condensadas e destacadas, conforme sugere Bardin (1977). Com as categorias de análise construídas, partimos para a inferência e a interpretação dos dados. Tais inferências foram realizadas por meio da desmontagem da mensagem produzida e da construção de um novo conteúdo, que foi realizado sob a ótica de um novo contexto, mas em articulação com as condições de produção da mensagem. 


\section{O tratamento da heterogeneidade em uma pedagogia coletiva: o que faziam as professoras?}

O tratamento da heterogeneidade de conhecimentos dos alunos sobre a leitura e a escrita na sala de aula será analisado, conforme dissemos anteriormente, a partir das ações que as professoras desenvolviam ante esse fenômeno. Para isso, consideraremos os momentos nos quais elas desenvolveram uma pedagogia coletiva, utilizando as mesmas atividades para todos os alunos, mas dirigiram, de algum modo, uma atenção diferenciada para alguns aprendizes.

As situações coletivas de ensino, com atividades padronizadas, foram bastante frequentes nas práticas de ambas as professoras. Apesar disso, pudemos observar, no interior dessas situações, um movimento de diferenciação nas ações docentes que considerava, de certa maneira, as necessidades de aprendizagem de determinadas crianças.

No caso da professora Beatriz, a atenção às necessidades de alguns alunos acontecia, principalmente, nos momentos de explicação da atividade ou do assunto estudado e, em especial, nas situações que envolviam a reflexão e a análise sobre a escrita de palavras. Já no caso da professora Irene, esse trabalho era mais frequente quando ela utilizava o livro didático e quando realizava a atividade de leitura de palavras. Nessas situações, a atenção das docentes era destinada a todos os alunos, embora também estivessem atentas às possíveis dificuldades de alguns aprendizes, pois, como explicita Perrenoud (2001, p. 90), "No discurso aparentemente dirigido a todo grupo, de fato coexistem fragmentos de discursos dirigidos mais particularmente a um subgrupo e até mesmo a um aluno em particular."

As interações que a professora Beatriz realizava com alguns de seus alunos nesses momentos de trabalho coletivo, conforme podemos observar no extrato a seguir, evidenciavam que ela tentava, por meio de questionamentos, fazê-los compreender o que não tinham compreendido. Nesse extrato, a docente solicitou que os alunos copiassem cinco palavras em ordem alfabética. Quando uma aluna disse não ter compreendido a solicitação, a docente interagiu com ela da seguinte maneira:

$\mathrm{P}^{2}$ - Aí, veja, Fernanda, a gente fez a atividade de colocar na ordem alfabética. Falamos sobre ordem alfabética. Colocar as letrinhas do alfabeto na sua ordem.

P - Só que aqui, Fernanda, a tia colocou cinco palavras. Pra você colocar essas palavras seguindo a ordem do alfabeto, a gente precisa observar a primeira letrinha de cada uma delas.

$\mathrm{P}$ - Qual é a primeira letrinha dessa palavra?

$\mathrm{AS}^{3}-\mathrm{C}$. 
P - Dessa? (A professora continuou perguntando o nome da letra inicial de cada palavra)

[...]

P - A gente já sabe a letrinha de cada palavra, então, agora, eu preciso saber qual é a primeira letra do alfabeto.

AS - A.

$\mathrm{P}$ - Então, Fernanda, qual dessas palavras começa com a letra A?

Fernanda - Aquela dali.

$\mathrm{P}$ - Leia ela pra mim.

AS - Avião.

$\mathrm{P}$ - Então, eu vou pegar a palavrinha avião e vou escrever aqui primeiro.

$\mathrm{P}$ - Por que ela vem primeiro? Porque a primeira letrinha dela é a letrinha A.

$\mathrm{P}$ - Qual é a próxima palavra que eu escrevo seguindo essa sequência?

$[\ldots]$

Como podemos observar, o procedimento adotado pela professora, nessas situações coletivas de ensino, era o de, nas interações com os alunos, construir apoios ou "andaimes" que permitissem a compreensão e a resolução da atividade. Embora a dificuldade partisse de um aluno, a reflexão era realizada, na maioria das vezes, coletivamente, com o intuito de envolver todos. Entendemos esse procedimento como um "esquema de ação", pois era adotado de forma regular pela docente nessas situações repetitivas, mas sempre singulares, de explicação da atividade ou, como veremos a seguir, do assunto estudado e de reflexão e análise sobre a escrita de palavras.

Nas situações de reflexão coletiva sobre palavras escritas pelos alunos, Beatriz interagia tanto com o aprendiz que apresentava dificuldade, sendo ele o alvo principal de sua intervenção, quanto com os demais, uma vez que promovia a reflexão no âmbito coletivo, conforme podemos observar no extrato de aula a seguir:

P - Venha agora aqui, Berenice. Tente escrever a palavra AZUL [a aluna escreve ZU].

$\mathrm{P}$ - Presta atenção no som. Na palavra AZUL, você só está ouvindo o som do U ou tem outra letrinha?

P - Escuta o som inicial: A-ZUL. Olha o som. A - ZUL. [A aluna não acrescenta nenhuma letra à palavra que havia escrito].

$\mathrm{P}$ - Deixa ela sentar pra prestar atenção no que faltou.

$\mathrm{P}$ - Veja, Beatriz, quando eu perguntei a você sobre o som inicial da palavra AZUL, A - ZUL, qual é o som inicial?

AS - A.

P - Aí "ZUL", que foi o "ZU" que você escreveu, mas tá faltando o que nessa palavrinha?

AS - O "L".

$\mathrm{P}$ - No começo ou no final?

AS - No final.

[...]. 
Essa prática de tratar a dificuldade singular no coletivo da sala de aula assemelha-se a um dos esquemas evidenciados por Goigoux (2001), ao analisar padrões de uma professora de alfabetização durante o curso de uma sequência de ensino de leitura. Nessa análise, um dos esquemas abordados refere-se ao "ajustamento e consideração do indivíduo no coletivo", o que contempla muitos aspectos realizados por Beatriz em suas práticas, como, por exemplo, incentivar a iniciativa das crianças; recuperar a fala do aprendiz e continuar o intercâmbio sobre o tema iniciado pelo aluno, deixando a iniciativa por conta dele próprio; tratar as dificuldades encontradas; prestar atenção nos estudantes com dificuldades; tratar publicamente e efetivamente uma dificuldade importante de um aluno; observar uma solicitação individual dentro do grande grupo, entre outros aspectos (GOIGOUX, 2001).

Já no caso da professora Irene, observamos que os momentos de leitura de palavras, que era uma atividade realizada no âmbito coletivo da classe, constituíam situações em que a docente intervinha de maneira diferenciada com alguns alunos. Para realizar essa atividade, a professora sempre escrevia no quadro as palavras que deveriam ser lidas pelos alunos e solicitava que, individualmente, realizassem a leitura da palavra que ela havia indicado.

Embora a atividade fosse feita coletivamente, percebemos as intervenções diferenciadas quando a professora conduzia esses momentos de maneira diferente com alguns alunos, o que nos mostrava a sua percepção sobre os diversos conhecimentos sobre a leitura e a escrita dos aprendizes. Quando propunha a leitura individual de palavras, a professora parecia ter consciência dos alunos que conseguiriam realizá-la autonomamente e daqueles que não conseguiriam fazê-la.

A intervenção diferenciada acontecia quando a professora chamava ao quadro aqueles discentes que não conseguiam realizar a leitura e conduzia esse momento com base nos conhecimentos que eles já possuíam. Nessas situações, ela pedia para o aluno ler a palavra e, caso ele não conseguisse, realizava outro procedimento, que consistia numa intervenção direta junto àquele aprendiz. É o que podemos observar no extrato a seguir:

P - Gente! Vamos ver (a professora escreveu no quadro a família silábica do Z e algumas palavras escritas com essa letra e pediu para que os alunos lessem coletivamente).

$\mathrm{P}$ - Gente, agora vamos ver. Presta atenção! (a docente escolheu alguns alunos para fazer a leitura individual. Leandro não conseguiu ler a palavra).

$\mathrm{P}$ - Que letra é essa, Leandro?

Leandro - A.

$\mathrm{P}-\mathrm{E}$ essa? (o aluno não soube responder)

$\mathrm{P}-$ Essas duas aqui? Hein? Eu quero essas duas. Que som é esse?

Leandro $-\mathrm{Z}$. 


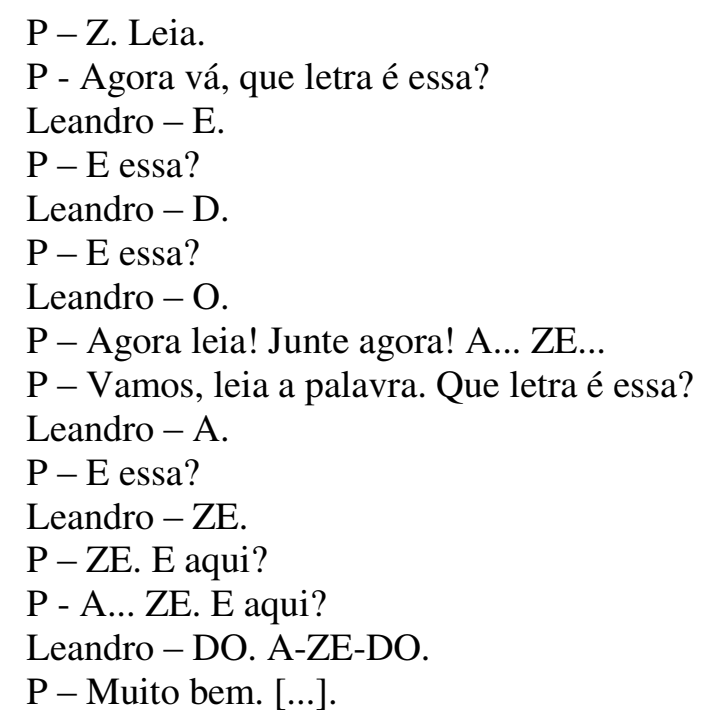

Diante da dificuldade do aprendiz, conforme evidenciado no extrato acima, a docente lançou mão de alguns procedimentos que levavam ao seu objetivo final, que era a leitura da palavra pelo aluno. Para isso, Irene inicia sua intervenção questionando-o sobre as letras, posteriormente sobre as sílabas, até chegar à leitura da palavra, que ocorreu com o apoio da retomada das duas primeiras sílabas lidas. Essas ações eram regulares nas práticas de Irene, configurando-se, assim, também, como um "esquema de ação" que era acionado sempre que a docente se deparava com as dificuldades de leitura de alguns aprendizes.

Esse esquema usado por Irene assemelha-se a um dos analisados por Goigoux (2001) no trabalho mencionado anteriormente e diz respeito ao "esquema de regulação da atenção dos alunos". Ao analisar esse esquema, algumas das orientações apresentadas puderam ser percebidas nas práticas de Irene, como, por exemplo: trazer um estudante para o quadro; atribuir uma tarefa para o aluno (vir mostrar uma palavra); dialogar publicamente com ele, atribuindo-lhe o papel de interlocutor potencial para todos os outros alunos da turma; tomar a sua proposta como tema de trabalho coletivo, dentre outros aspectos (GOIGOUX, 2001).

Embora se apoiasse em procedimentos de ensino considerados tradicionais, como a repetição das famílias silábicas, a docente parecia reconhecer as diferenças entre os alunos e tentava conduzir as suas ações de maneira a atingir as necessidades deles. Com isso, parecia evidenciar práticas respaldadas em uma coerência pragmática (CHARTIER, 2007a), compatibilizando uma perspectiva tradicional de alfabetização, que tem como um de seus princípios a homogeneização, e outra que considera, de algum modo, a singularidade dos aprendizes. Em suma, desenvolvia práticas que remetiam a perspectivas teóricas diferentes, mas que pareciam fazer sentido para a docente em seu trabalho em sala de aula. 
As intervenções que Irene realizava aconteciam apenas com aqueles aprendizes que apresentavam dificuldades, evidenciando a preocupação da docente em diferenciar o ensino e envolver os alunos que mais necessitavam de ajuda. No caso dos aprendizes que conseguiam realizar autonomamente a leitura de palavras e até mesmo de textos, a professora não dedicava nenhuma atenção diferenciada.

A professora Beatriz também mobilizava esse esquema de ação em sua prática, no entanto as intervenções caracterizavam-se como monitoramento das resoluções das atividades dos alunos, de um modo geral, ou como uma ajuda direcionada a alunos com alguma dificuldade. Nesse último caso, as ajudas eram realizadas ora diretamente pela própria professora, ora mediante a orientação para que os alunos se organizassem em pares para resolução de algumas atividades.

No que diz respeito aos monitoramentos, que eram as ações voltadas para o conjunto da sala de aula, Beatriz sempre se preocupava em observar como as crianças estavam respondendo as atividades, principalmente quando se tratava da escrita de palavras. Por isso, quando propunha tais atividades, sempre passava por entre as bancas para observar as respostas dos alunos. À medida que observava os erros, questionava os aprendizes, levando-os a perceber, por si próprios, o que deveria ser corrigido (por exemplo, letras que faltavam nas palavras ou que estavam trocadas).

Assim, a professora procurava, nas situações coletivas de ensino, atentar para os aprendizes que apresentavam alguma dificuldade, realizando intervenções direcionadas a eles. Para isso, além de monitorar as respostas dos alunos, a docente ajudava diretamente esses aprendizes ou então colocava outros alunos para realizar essa ajuda, evidenciando que "É preciso saber escolher, renunciar a algumas intervenções inúteis, diferenciar as intervenções menos urgentes para atender ao mais necessitado." (PERRENOUD, 2001, p. 46).

Essa ação de colocar outros alunos para realizar a ajuda aos aprendizes que apresentavam dificuldades de aprendizagem caracterizava-se como outro "esquema de ação" mobilizado por Beatriz: os agrupamentos. Tais agrupamentos geralmente eram realizados com o intuito de os alunos estabelecerem relações de ajuda mútua na resolução das atividades. Por isso, Beatriz autorizava a ajuda, mas alertava para que um dos colegas não fizesse a atividade pelo outro.

Fabíola e Daniel, crianças com necessidades educativas especiais, sempre eram agrupadas com outros colegas. Assim, à medida que a docente trabalhava com o coletivo da classe, também considerava as necessidades desses aprendizes, que eram reunidos a outras crianças que pareciam ter níveis de conhecimentos próximos, o que possibilitava a oportunidade de estabelecer interações 
cooperativas. Segundo Colomina e Onrubia (2004, p. 292), esse tipo de interação “[...] se apoia precisamente na delegação da autoridade por parte do professor e na cessão aos alunos de uma parte essencial do controle e da responsabilidade sobre o que ocorre na sala de aula e sobre o processo de ensino e aprendizagem".

Esses agrupamentos também aconteciam quando Beatriz trabalhava com o livro didático, que se caracteriza por ser um material padronizado. Com isso, a estratégia do agrupamento era utilizada, ao que parece, para, em meio à situação coletiva de uso do livro didático, atender às dificuldades de alguns alunos. Isso parece evidenciar, portanto, a preocupação de Beatriz em envolver todos nas atividades propostas. Todavia, os agrupamentos e as interações entre os alunos caracterizavam-se, muitas vezes, mais pelo fornecimento de respostas imediatas (de um aluno ao outro) ou pela cópia de respostas, sem que houvesse reflexão por parte de quem estava sendo ajudado.

Inferimos que as interações aconteciam dessa maneira devido ao fato de os agrupamentos realizados pela docente aproximarem, às vezes, alunos que apresentavam conhecimentos muito distintos sobre a escrita. Consideramos que esses agrupamentos pareciam pautar-se mais, em alguns casos, nas circunstâncias do momento, e não em algo previamente programado. Nessas situações, os alunos agrupados em duplas sentavam-se próximos, um ao lado do outro, o que parecia impulsionar Beatriz a agrupar dois alunos com níveis de conhecimento muito distintos para a resolução da atividade do livro didático.

Entretanto, isso não aconteceu em uma das aulas, na qual a docente solicitou que um aluno com mais conhecimentos sobre a leitura e a escrita ${ }^{4}$, que estava sentado na última banca, ajudasse um colega que se localizava na primeira carteira e tinha um conhecimento mais inicial. Isso nos leva a concluir que os agrupamentos realizados pela professora não eram sempre feitos de maneira circunstancial, isto é, considerando apenas a proximidade das crianças do ponto de vista da localização.

Percebemos, então, que a docente realizava esses agrupamentos, em alguns momentos, como uma forma de facilitar a organização do trabalho pedagógico (agrupar alunos que estavam sentados próximos). Nessa perspectiva, podemos analisar alguns dos agrupamentos feitos pela professora como escolhas pedagógicas, ou seja, "conhecimentos de tipo pedagógico" (CHARTIER, 2007a) que direcionavam, na nossa perspectiva, em alguns momentos, as cooperações na sala de aula.

No caso da professora Irene, observamos, ainda, uma ação que se caracterizava não propriamente como um esquema de ação, mas, sim, como uma "tática" (CERTEAU, 1994). Ao usar o livro didático, a docente mediava o trabalho com esse material e, às vezes, adaptava as suas 
orientações, de modo a atender às necessidades de sua turma. Isso se tornou claro quando ela não seguia a orientação para que a leitura fosse realizada pelos próprios alunos e ela mesma a realizava, modificando, assim, o instituído pelo material didático.

Nesse sentido, a docente desenvolvia uma ação calculada que se inseria no âmbito da ausência de poder. Por isso, jogava com um terreno imposto, aproveitando as ocasiões para subverter o prescrito e estipular suas próprias regras. Assim, o lugar da "tática" ou, melhor dizendo, esse "não-lugar", conforme pontua Certeau (1994, p. 100), permite uma mobilidade nas práticas a serem desenvolvidas e a professora parecia organizar as suas ações de modo a envolver aqueles alunos que ainda não conseguiam ler autonomamente os textos das atividades do livro.

Em síntese, os esquemas de ação mobilizados pelas professoras mostravam-se como ações regulares que eram desenvolvidas com vistas a contemplar as diferentes necessidades de aprendizagem dos seus alunos em sala de aula. Tais ações vão sendo mobilizadas e retomadas nas práticas frente a diferentes situações e tramas que são análogas a outras experiências que o professor experiente vivencia no espaço escolar ante o desafio de ensinar a todos e a cada um.

\section{Considerações finais}

Ao analisar as maneiras de fazer mobilizadas pelas docentes no cotidiano da sala de aula, percebemos que a heterogeneidade não era um fenômeno indiferente às suas ações. No interior das situações coletivas de ensino, ambas as professoras faziam um movimento para atender aos aprendizes que necessitavam de uma atenção diferenciada concomitantemente ao trabalho desenvolvido com o restante da classe. Nesse sentido, observamos as intervenções, os monitoramentos, as ajudas e os agrupamentos, assim como as táticas, como maneiras de atender às necessidades de aprendizagem de alguns alunos.

Com isso, podemos concluir que as professoras parecem estar tentando encontrar maneiras de lidar com o fenômeno da heterogeneidade, mobilizando esquemas de ação e táticas com vistas a dar conta desse fenômeno na sala de aula. Segundo Duran (2007, p. 126), “As invenções cotidianas que ocorrem na escola representam as diferentes formas de os professores se ajustarem às políticas que lhes são impostas, às diferentes formas de 'caça não-autorizada' que vai reorganizando o cotidiano de suas práticas." 


\section{Notas}

${ }^{1}$ A escolha dessas professoras ocorreu mediante a indicação da Secretaria de Educação do município de Caruaru, que indicou professoras consideradas, pela rede municipal de ensino, como boas alfabetizadoras. Em outras palavras, professoras que, ao final do ano letivo, conseguiam bons rendimentos, no que se referia à alfabetização das crianças. Além disso, também buscamos encontrar essas boas alfabetizadoras por meio da indicação de professoras e coordenadoras que atuavam na rede municipal de ensino.

${ }^{2}$ Utilizamos a letra "P" para nos referirmos à professora.

${ }^{3}$ Utilizamos as letras "AS" para nos referirmos a todos os alunos.

${ }^{4}$ Antes de iniciarmos as observações das práticas de alfabetização de ambas as professoras, realizamos com os alunos 04 (quatro) atividades diagnósticas (escrita de palavras; leitura de palavras; leitura de texto; escrita de texto) que permitiram caracterizar os diferentes conhecimentos sobre leitura e escrita desses alunos, assim como traçar um perfil das duas turmas.

\section{REFERÊNCIAS}

ANDRÉ, M. Etnografia da prática escolar. Campinas: Papirus, 1995.

BARDIN, L. Análise de conteúdo. Lisboa: Edições 70, 1997.

BARRETTO, E. S. S. \& SOUSA, S. Z. Estudos sobre ciclos e progressão escolar no Brasil: uma revisão. Educação e Pesquisa, São Paulo, v. 30, n.1, p. 11-30, jan./abr., 2004.

BATISTA, A. A. G.; GALVÃO, A. M. O.; KLINK, K. Livros escolares de leitura: uma morfologia (1866-1956). Revista Brasileira de Educação, Rio de Janeiro, nº 20, maio/ago. 2002.

CERTEAU, M. A invenção do cotidiano: artes de fazer. 5. ed. Petrópolis: Vozes, 1994.

CHARTIER, A. M. Fazeres ordinários da classe: uma aposta para a pesquisa e para a formação. Educação e Pesquisa, São Paulo, v. 26, n. 2, p. 157-168, jul./dez, 2000.

CHARTIER, A. M. Práticas de leitura e escrita: história e atualidade. Belo Horizonte: Ceale/Autêntica, p. 185-207, 2007a.

CHARTIER, A. M. L’ école et la lecture obligatoire. Paris: Retz, $2007 \mathrm{~b}$.

COLOMINA, R.; ONRUBIA, J. Interação educacional e aprendizagem escolar: a interação entre alunos. In: COLL, C. et al (Orgs.) Desenvolvimento psicológico e educação. 2. ed. Porto Alegre: Artmed, 2004.

DURAN, M. C. G. Maneiras de pensar o cotidiano com Michel de Certeau. Diálogo Educ., Curitiba, v. 7, n. 22, p. 115-128, set./dez, 2007.

FERREIRO, E. Reflexões sobre alfabetização. 24. ed. São Paulo: Cortez, 2001. 
FERREIRO, E.; TEBEROSKY, A. Psicogênese da língua escrita. Porto Alegre: Artmed, p. 191-245, 1999.

FILHO, L. M. F.; VIDAL, D. G. Os tempos e os espaços escolares no processo de institucionalização da escola primária no Brasil. Revista Brasileira de Educação, Rio de Janeiro, n. 14, maio/ago, 2000.

GOIGOUX, R. Analyser l'activité d'enseignement de la lecture: une monografhie. Revue Française de Pédagogie, n.138, p. 125-134, jan./mar., 2002.

GOIGOUX, R. Lector in didactica: Un cadre théorique pour l'étude de l'activité du maître de lecture. In : BERNIÉ, Jean-Paul (Org.). Apprentissage, Développement et significations. Presses Universitaires de France, p. 129-153, 2001.

MAINARDES, J. A escola em ciclos: fundamentos e debates. São Paulo: Cortez, 2009.

MORAIS, A. G. Sistema de escrita alfabética. São Paulo: Melhoramentos, 2012.

PERRENOUD, P. A pedagogia na escola das diferenças: fragmentos de uma sociologia do fracasso. Porto Alegre: Artmed, p. 15-111, 2001.

TARDIF, M. Saberes docentes e formação profissional. 9. ed. Petrópolis: Vozes, p. 31-53, 2008. 


\section{The Treatment of Heterogeneity in a Collective Pedagogy: How to create literacy teachers}

\begin{abstract}
Abtract
This study is included in the discussions about teaching knowledge and practices as regard the heterogeneity of knowledge about reading and writing of learners. In this direction, we seek to understand the actions mobilized for literacy teachers, amid the collective and standardized situations of teaching, to treat the learning needs of some students. For that, we analyze the practices of two teachers from the 1st year of elementary school of the education system of the city of Caruaru-PE, Brazil, taking, as theoretical and methodological way, the qualitative research approach. The data from the research, treated through thematic content analysis and obtained through semi-structured interviews and observations in the classroom, demonstrated the use of some "action schemes" by teachers for, amid collective and standardized situations of teaching, meet the needs of some students.
\end{abstract}

Keywords: Literacy. Heterogeneity. Practices.

\section{Le traitement de l'hétérogénéité dans une pédagogie collectif: manières de faire des instituteurs}

\section{Résumé}

Cette étude s'inscrit dans le cadre des discussions sur les savoirs et les pratiques des enseignants concernant à l'hétérogénéité des connaissances sur la lecture et l'écriture des apprentis. Dans ce sens, nous cherchons à comprendre les actions mobilisées par des instituteurs, au cœur des situations collectives et standardisés d'enseignement, pour répondre aux besoins d'apprentissage de certains élèves. Pour cela, nous analysons les pratiques de deux enseignants du cours préparatoire du réseau scolaire de la ville de Caruaru, Pernambouc, au Brésil, en adoptant, comme chemin théorique et méthodologique, l'approche qualitative de recherche. Les données de la recherche, traités à travers l'analyse de contenu thématique et obtenus grâce à des interviews et des observations semi-structurées en classe, ont montrés l'utilisation de certains «schémas d'action» et tactiques de la part des enseignants, dans des situations collectives et normalisées d'enseignement, de répondre aux besoins de certains élèves.

Mots-clés: L'alphabétisation. Hétérogénéité.

Pratiques.
Nayanne Nayara Torres da Silva

E-mail: nayannetorres@yahoo.com.br

\author{
Alexsandro da Silva \\ E-mail: alexs-silva@hotmail.com
}

Recebido em: 22/12//2015

Versão final recebida em: 31/08/2016

Aprovado em: 08/10/2016 